\begin{tabular}{|c|c|}
\hline & $\begin{array}{l}\text { International Journal of Trend in Scientific } \\
\text { Research and Development (IJTSRD) }\end{array}$ \\
\hline 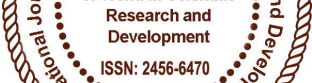 & International Open Access Journal \\
\hline 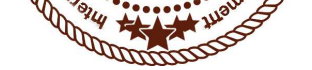 & ISSN No: 2456 - 6470 | www.ijtsrd.com | Volume - 2 | Issue - 2 \\
\hline
\end{tabular}

\title{
An Efficient Smart Garbage Disposal System - A Review
}

\author{
Abhijeet Gothankar, Shubham Katkar, Swapnatej Pawar, Tejaskumar Dhalmare, Suhasini Goilkar \\ Department of Electronics \& Telecommunication Engineering, \\ Finolex Academy of Management \& Technology, Ratnagiri, Maharashtra, India
}

\section{ABSTRACT}

In the recent decades, Urbanization has increased tremendously. At the same phase there is an increase in waste production. Waste management has been a crucial issue to be considered. This review paper is a way to achieve this good cause. In this review paper, smart bin is built on a microcontroller based platform. Microcontroller would be programmed in such a way that it could control the operations of servo doors. This microcontroller would control allethree components of our project. The basic idea of our project is the van could move around area given to it. The van is basically a line following robot which would stop at certain intervals below the container, the container would drop off the garbage into the van. The van would go to next station and drop the garbage into the dumping pit. Once these smart bins are implemented on a large scale, by replacing our traditional bins present today, waste can be managed efficiently as it avoids unnecessary lumping of wastes on roadside .Foul smell from these rotten wastes that remain untreated for a long time, due to negligence of authorities and carelessness of public may lead to long term problems. Breeding of insects and mosquitoes can create nuisance around promoting unclean environment. This may even cause dreadful diseases.

Keywords: Microcontroller, GSM/GPRS modem, Ultrasonic sensor, garbage dustbin

\section{INTRODUCTION}

Though the world is in a stage of up gradation, there is yet another problem that has to be dealt with.
Garbage! Pictures of garbage bins being overfull and the garbage being spilled out from the bins can be seen all around. This leads to various diseases as large number of insects and mosquitoes breed on it. A big challenge in the urban cities is solid waste management. Hence, smart dustbin is a system which can eradicate this problem or at least reduce it to the minimum level. Our present Prime Minister of India, Shri Narendra Modiji has introduced the concept of implementing 100 smart cities in India. Swachh Bharat Abhiyan was initiated to ensure a clean environment. Majority of viruses and bacterial infections develop in polluted environment. Safeguarding the environment using technology sources is needed at present. Majority of the public environment seems to be polluted with the waste material.

Dustbin is a common means and a basic need everywhere. It is observed that often the garbage gets collected, due to irregular removal of garbage present in the dustbin. So we have to think for the solution on this problem.

\section{LITERATURE SURVEY}

Monika K.A. and her team have made a quantitative analysis between existing dustbins and their serving population. In this paper, GSM 900A modem is used to send the messages. It consists of a GSM/GPRS modem with standard communication interfaces like RS-232 (Serial Port), USB, so that it can be easily connected to the other devices. The ultrasonic sensor 
is used to find the height of garbage filled at different intervals of time. [1]

GSM 900A modem is used to ship the messages. It includes a GSM/GPRS modem with preferred communication interfaces like RS-232 (Serial Port), USB, so that it may be without problems connected to the other devices. The ultrasonic sensor is used to find the peak of garbage stuffed at exclusive durations of time. In this paper, GSM 900A modem is used to deliver the messages. It includes a GSM/GPRS modem with desired communication interfaces like RS-232 (Serial Port), USB, in order that it can be without problems connected to the opposite devices. The ultrasonic sensor is used to discover the height of rubbish filled at distinctive durations of time. [2]

Each garbage bin is given a no. of id which stores in database with its location. Weighing sensor is used measure the load placed of the garbage bin. A/D converter compares the set limit with input data. If received threshold level send message to the server through GSM. After receiving message by the server the waste disposal vehicle reaches to the desired location. Then disposal vehicle collect the garbage. [3]

In this, system is basically based on PIC16F877A Microcontroller. The input from various sensors goes to the microcontroller and output of microcontroller is given to the GPRS module and Compressor. In this project IOT Garbage Monitoring system is a very innovative system which will help to keep the cities clean. This system monitors the garbage bins and informs about the level of garbage collected in the garbage bins via a web page. [4]

The improved Garbage bins will contain Arduino kit with power supply, Ultrasonic sensor on the top of garbage bin. The working will be to capture the certain level of garbage filled inside the bin. The sensors will detect the level and it will pass the information to the Base Station of the area manager by sending information about the details of Trash, its location. On receiving the information the area manager can immediately deploy a pickup vehicle (GPS enabled) to clean the garbage bin. The bin gets cleaned a message of cleaning of that particular bin will be sent to the area manager. [5]

Intelligent Monitoring System for Garbage Waste bins . In this proposed system there are multiple dust bins are located throughout the city, this dust bins are provided with low cost embedded devices. Global system for mobile communication is the latest tread used now a days can be used for our project. Sensors are placed above the dust bin. It will detect whether the garbage is at low, middle or highest level. The main control unit consist of Arduino it will receive the output signal of sensor, process it and according to that it will send the message to office user. Along with detection of depth of garbage simultaneously it will detect presence of flame or smoke. [6]

In this project IOT Garbage Monitoring system is a very innovative system which will help to keep the cities clean. This system monitors the garbage bins and informs about the level of garbage collected in the garbage bins via a web page. The web page gives a graphical view of the garbage bins and highlights the garbage collected in colour in order to show the level of garbage collected. IR sensors and ultrasonic sensors are also helpful for this system. The IR Sensor-Single is a general purpose proximity sensor. Here, we use it for collision detection. The module consists of an IR emitter and IR receiver pair. The high precision IR receiver always detects an IR signal. Ultrasonic ranging module provides $2 \mathrm{~cm}-400 \mathrm{~cm}$ non-contact measurement function, the ranging accuracy can reach to $3 \mathrm{~mm}$. The modules include ultrasonic transmitters, receiver and control circuit. [7]

Every smart bin is equipped with ultrasonic sensors which measure the level of dustbin being filled up. The container is divided into three levels of garbage being collected in it. With its continuous use the levels get filled up gradually with time. Every time the garbage crosses a level the sensors receives the data of the filled level. This data is further send to the garbage analyser as instant message using GSM module. Every message which is received at the garbage analyser end is being saved as data which is further used for the process of analysis and predictive modelling. The data received at real time is used by the application interface for better viewing of the filled level. The data received is saved in the database keeping all its attributes intact as time and date. A history of data collected in months is used by the department of data analysis for prediction and report making. The application interface shows the real time level to the garbage analyser and using that it directs its team of garbage collector to collect the garbage to avoid overflow. The prediction model is designed to 
predict the time in which the every level of container will be filled in future. This will help the waste management department to optimize the route for the collection of waste every time garbage collector moves around the city for garbage collection. This helps in saving time, resources of the waste department and work is then performed in more efficient manner. [8]

The implementation of smart garbage management system using sensors, microcontrollers and GSM module assures the cleaning of dustbins soon when the garbage level reaches its maximum. If the dustbin is not cleaned in specific time, then the record is sent to the higher authority who can take appropriate action against the concerned contractor. This system also helps to monitor the fake reports and hence can reduce the corruption in the overall management system. This reduce the total number of trips of garbage collection vehicle and hence reduce the overall expenditure associated with the garbage collection. It ultimate helps to keep cleanness in the society. Smart collection bin works with the sensors will show us the various levels of garbage in the dustbins and also the weight sensor gets activated to send its output ahead when its threshold level is crossed. If dustbins are not cleaned in time, the details will be forwarded to higher authority. Different implementation methods - are explained in the remaining parts. The remaining part of the paper is organized as follows. In Section II survey of all methods will be described in detail. The paper concludes with a brief summary in section III. [9]

Here we have figured out a new model for the municipal dustbins which intimates the centre of municipality for immediate cleaning of dustbin. This dustbin is also designed to compress the garbage periodically thus preventing the unnecessary occupying of dustbin $\mathrm{s}$ space by light weighted but space occupying garbage particles like sponges, etc. A leaf switch is pressed by the garbage when it reaches a particular level and an Arduino Uno is programmed in such a way that when the garbage reaches this particular level, intimation is given to the central hub in the form of glowing of LED. [10]

In our daily life, we see the pictures of garbage bins being overfull and all the garbage spills out resulting in pollution. This also increases number of diseases as large number of insects and mosquitoes breed on it. So they have built a project by using a combination of
ZigBee and Global System for Mobile Communication. Hence, a combination of both of these technologies is used in the project. To give a brief description of the project, the sensors are placed in the common garbage bins placed at the public places. When the garbage reaches the level of the sensor, then that indication will be given to ARM 7 Controller. The controller will give indication to the driver of garbage collection truck as to which garbage bin is completely filled and needs urgent attention. ARM 7 will give indication by sending SMS using GSM technology. [11]

The proposed system would be able to automate the solid waste monitoring process and management of the overall collection process using IOT (Internet of Things). It consist of four main subsystems namely Smart Trash System (STS), Local Base Station (LBS), Vehicle System (VS) and Smart Monitoring and Controlling Hut (SMCH).Whenever the waste bin gets filled this is acknowledged by placing ZigBee at the waste bin, which transmits it to the receiver at the desired place in the area or spot. The received signal indicates the waste bin status at the monitoring and controlling system. [12]

\section{PROBLEM DEFINITION}

Due to concept of clean city and green city the garbage bins in the city are being removed. And the garbage collecting trucks come in between 9 to 5 , so a problem faced by all is deposition of garbage. So we have come up with this idea.

\section{BLOCK DIAGRAM}
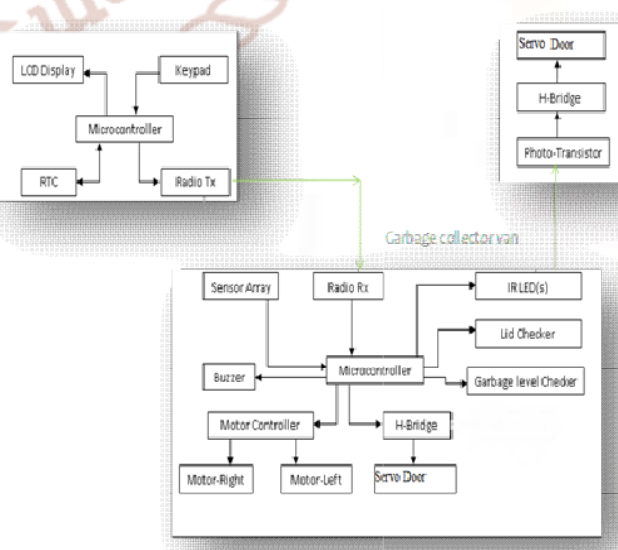

\section{Components}

Smart Bin is built on Microcontroller based platform. The microcontroller is interfaced with motor 
controller, sensor array, LED, keypad, servo motor, etc.

\section{A. Microcontroller}

A microcontroller is a small computer on a single integrated circuit. The PIC16F876/873 devices come in 28-pin packages and the PIC16F877/874 devices come in 40-pin packages. The Parallel Slave Port is not implemented on the 28-pin devices.

There are three memory blocks in each of the PIC16F87X MCUs. The Program Memory and Data Memory have separate buses so that concurrent access can occur and is detailed in this section.

The PIC16F87X devices have a 13-bit program counter capable of addressing an $8 \mathrm{~K} \times 14$ program memory space. The PIC16F877/876 devices have $8 \mathrm{~K}$ $\mathrm{x} 14$ words of FLASH program memory, and the PIC16F873/874 devices have 4K x 14. Accessing a location above the physically implemented address will cause a wraparound. The RESET vector is at $0000 \mathrm{~h}$ and the interrupt vector is at $0004 \mathrm{~h}$.

\section{B. IR Sensors}

The IR Sensor is a general purpose sensor. Here we use this IR sensor for collision detection. The IR Sensor module consists pair of an IR emitter and IR receiver. The high precision IR receiver always detects an IR signal. The module contains LM324 comparator IC for the comparison of threshold value and output value. The output of sensor is high whenever it IR frequency and low otherwise. The onboard LED indicator helps user to check status of the sensor without using any additional hardware.

Power consumption of this pair is comparatively low and output of this pair is can be obtain in digital form.

\section{METHODOLOGY}

\section{Level 1- building the container}

A box is made where the garbage is to be deposited. It has a two servo doors. Upper and lower. The container is placed at a certain height from above the ground because the garbage collecting van should pass from below it.

\section{Level 2 - Remote Control}

This is used to start the garbage collecting van
Level 3 - Van

The van starts from the given position. Stops below the container. Firstly the upper lid of the van is opened. It is controlled by microcontroller. The door of the container opens and the garbage falls in van. The lid is closed. Nextly the van starts again and goes towards next station. After completing the stations the van move towards the dumping pit, Dumps the garbage and again starts from the desired location.

\section{CONCLUSION}

By implementing this project we will be able to automatically control the disposal of garbage, according to that we can collect garbage of particular area, which will avoid overflow conditions and helps to reduce pollution as well as different hazards of health. This system will reduce the wastage of fuel by reducing number of trips of garbage collection vehicle. Hence this system will makes the garbage collection more efficient.

\section{REFERENCES}

1. Monika, Nikitha Rao, Prapulla, Shobha 'Smart Dustbin-An Efficient Garbage Monitoring System' Department Computer Science and Engineering R $\mathrm{V}$ College of Engineering, India, DOI 10.4010/2016.1694 2016 IJESC

2. V.PurushothamVijaynaidu, T.Dhikhi, Saveetha School of Engineering, Saveetha University, Chennai SMART GARBAGE MANAGEMENT SYSTEM, IJPT Dec-2016 | Vol. 8 | Issue No.4 | 21204-21211

3. P M.Palkar, T. Pathan, Ankita P. Hedaoo , Kalyani A. Harode, Nutan M. Petkule, Pranjali P. Kakade, Pranita D. Kolhe,Electronics and Communication Engg., PBCOE, Maharashtra, India IJARIIE-ISSN(O)-2395-4396, Vol-3 Issue-2 2017

4. Akshay Goyala, Kshitij Shinghalb, Aastha Guptac, Akash Diwakard, Kanika Rastogid, Smart Bin , International Journal of Innovative and Emerging Research in Engineering Volume 4, Issue 5, 2017

5. Chaitanya More, Darshan Mestry, Parag Kedia, Reshma More, Efficient garbage collection using wsn IJRET: International Journal of Research in Engineering and Technology eISSN: 2319-1163 | pISSN: 2321-7308 
6. R.B.Tapase, Ashwini Mohite, Trupti Kadam, Puja Deshmukh., Intelligent monitoring system for garbage waste bins using arduino IJRET: International Journal of Research in Engineering and Technology eISSN: 2319-1163 | pISSN: $2321-7308$

7. Jyoti Savakare, Shubhangi Solunke, Rahul Tagalpallewar, Mahesh Bhagwat. Smart Garbage Monitoring System with Compressing Mechanism, International Engineering Research Journal (IERJ) Volume 2 Issue 3,2016, ISSN 2395-1621

8. Narayan Sharma, Nirman Singha, Tanmoy Dutta, Smart Bin Implementation for Smart Cities, International Journal of Scientific \& Engineering Research, Volume 6, Issue 9, September-2015, pp.787-791.

9. Ruhin Mary Saji, Drishya Gopakumar, Harish Kumar , K N Mohammed Sayed, Lakshmi. A Survey on Smart Garbage Management in Cities using IoT International Journal of Engineering and Computer Science ISSN: 2319-7242 Volume 5 Issue 11 Nov. 2016, Page No. 18749-18754

10. Twinkle Sinha,Mugesh Kumar, P.Saisharan, Smart Dustbin , International Journal of Industrial Electronics and Electrical Engineering, SRM University, India, vol-3, Issue-5, 2015,pp.101-104.

11. Kanchan Mahajan, Prof.J.S.Chitode Waste Bin Monitoring System Using Integrated Technologies. International Journal of Innovative Research in Science, Engineering and Technology, ISSN 2319-8753

12. Harshitha Naik, Akshata Rajashankar IOT based automatic waste management system. iisc.ernet.in/spp/39_series/SPP39S/02_Exhibition

_Projects/236_39 